\section{Graduate Student Professional Development: A Case Study}

\author{
Hector Eduardo Pérez ${ }^{1}$ and \\ Kent D. Kobayashi ${ }^{2}$
}

AdDitional INDEX words. graduate education, career development, teaching method, seminar, critical thinking

Summary. Graduate students within the Tropical Plant and Soil Sciences Department at the University of Hawaii at Manoa developed a program that addressed their concerns regarding career enhancement and planned a Professional Development Seminar Series. Students identified topics related to enhancing their overall graduate experience and professional development, such as ethics in research, leadership in graduate school and beyond, interviewing skills, and writing critically for publications. Experts from the University of Hawaii and business communities presented 35- to 40-minute seminars on the various topics. Expectations of the students included participation in discussion sessions and completion of a critical thinking exercise after each presentation. Course evaluations revealed that the new seminar series was considered to be as effective as established courses within the department. On a scale from $1=$ strongly disagree to $\mathbf{5}$ = strongly agree, students learned to value new viewpoints $[4.2 \pm 0.8($ mean $\pm S D)]$, related what they learned in class to their own experiences $(4.5 \pm 0.8)$, and felt the course was a valuable contribution to their education $(4.4 \pm 0.9)$. Students suggested offering the course during fall semesters to incoming students, reinforcing of the critical thinking exercise, and making the course mandatory for first-year graduate students.

\footnotetext{
Department of Tropical Plant and Soil Sciences, University of Hawaii at Manoa, 3190 Maile Way, St. John 102, Honolulu, HI 96822.

We thank John Gartrell and George Jarvis for provid ing constructive comments on this manuscript and Cynthia Nazario, Peter Toves, and Justin Meyer for their help in designing the Professional Development Seminar Series.

${ }^{1}$ Graduatestudent. To whom reprint requests should be addressed. E-mail address: hperez@hawaii.edu

${ }^{2}$ Associate professor.
}

A discrepancy between effective professional development and graduate student education occurs in universities and colleges today. The inconsistency is more significant in programs offering traditional academic degrees, such as MA, MS, and PhD, than in professional schools (e.g., law and medicine) (Poock, 2001). This problem is shared by disciplines and departments and is not confined to North America (Gonglewski and Penningroth, 1998).

Routinely, graduate curricula do not progress beyond research-oriented skills and ideas or scientific aspects of a given field. A survey of 4114 doctoral students in 11 disciplines and 27 institutions found seven out of 10 felt prepared to become independent researchers. However, the graduate student respondents commented that they did not feel well prepared for teaching higher-level courses and wanted more interdisciplinary experience. Furthermore, they viewed their skills as inadequate in professional practices such as assigning authorship on papers and avoiding financial and ethical conflicts of interest (Golde and Dore, 2001; Mervis, 2001).

In another survey, less than $20 \%$ of doctoral students felt they had sufficient training in workplace skills such as teamwork, collaboration, organization, and management (Gaff, 2002). Additionally, technical skills acquired during graduate school only account for about $7 \%$ of the total skill set required for being a successful professional (Stanley and Higley, 2000 ). Students need to enhance their graduate experiences with information and ideas regarding their development within academic and nonacademic settings to gain a selective advantage. However, obstacles to graduate student professional development exist.

Discussion with master's and doctoral candidates $(\mathrm{n}=10)$ in the Tropical Plant and Soil Sciences Department (TPSS) at the University of Hawaii at Manoa (UHM) revealed some barriers to enhancing professional development. For example, students felt that given time restraints associated with research, coursework, employment, and, in some cases, families, they would not have enough time to pursue activities regarding professional development. Discussants also identified a lack of communication between graduate students, as a cohesive group, and faculty regarding expectations of professionals in academic and nonacademic settings.

Current graduate students, but especially new and incoming students, mentioned that they were not aware of on-campus resources capable of assisting with professional development. Discussants questioned if most graduate students were self-motivated enough to engage in professional development. Also, many students felt that mentors did not adequately discuss professional development. Finally, international students (e.g., Filipino, Chinese) suggested that language and native customs are barriers to professional development.

Various approaches have been suggested to address the issue of graduate student professional development. For example, graduate schools should introduce students to professional and life planning (Gregory, 1994). Seminars should be created that help graduate students develop effective teaching skills (Darling and Earhart, 1990), and organized professional development workshops, offered as credit-bearing courses through a centralized graduate school, should be created (Poock, 2001 ). Independent of these suggestions, a team of graduate students from the University of Florida (UF) created and implemented a successful course in professional development for graduate students (Skelly et al., 2002). As a member of the team that helped create the UF course, I observed its positive impact on my colleagues and was able to enhance my graduate experience and professional development.

At UHM we implemented a modified version of the UF Professional Development Course within TPSS. Our objective was to evaluate student response to a new seminar course in professional development. This information would assist in determining if the course should be repeated.

\section{Materials and methods}

Graduate students in TPSS met to formulate topics for a Professional Development Seminar Series. Thirteen topics related to their needs were selected (Table 1). To identify expert speakers within the university community, we solicited suggestions from departmental faculty and college administrators. Once the speakers had committed to give presentations, we created a syllabus that included course 
objectives and format, expectations, and responsibilities of students. We adapted our course to include a critical thinking exercise (Table 2).

Speakers presented seminars weekly throughout the Spring 2003 semester and chose the style of their presentation. Each student was expected to participate in 15-min question and discussion sessions during or after each 35- to 40-min seminar. Furthermore, students were responsible for turning in a critical thinking exercise of the previous week's seminar before class began the following week. Grades were based on written critiques and class participation.

We administered course evaluations on the last day of class, using the university's Course and Faculty Evaluation (CAFÉ) System. The evaluation consisted of three questions mandated by the university and 20 questions selected by course administrators. For the 20 selected questions, students responded from $\mathrm{l}$ = strongly disagree to $5=$ strongly agree. Open-ended questions, appended to the evaluation forms, allowed further student input. Additionally, two students led a class discussion in which constructive criticism about the course was offered. We analyzed mean scores of the same evaluation questions used in TPSS 667 and other TPSS courses using a Kruskal-Wallis (chi square approximation) test.

\section{Results}

In all, 20 students enrolled for the seminar series. Of those enrolled, 19 were graduate students ( $84 \%$ from TPSS) and one was an undergraduate student from outside the College of Tropical Agriculture and Human Resources (CTAHR). Although response was low $(\mathrm{n}=1 \mathrm{l})$, most likely due to timing of evaluations, students indicated the seminar series was important and valuable in helping enhance their graduate experience and professional development. When comparisons to other TPSS courses could be made (Table 3), mean scores for this course (TPSS 667) were not significantly different $\left(\chi^{2}=3.2, \mathrm{df}=1, P=0.074\right)$ than mean scores of other established courses in the department. Mean score in another group of questions (Table 4), where no comparisons could be drawn to other TPSS courses, ranged from 3.9 to 4.4 , and were comparable to scores in Table 3 . When asked for

Table 1. Topics and expert speaker affiliations for 35- to 40-min presentations made in the Professional Development Seminar Series offered during the Spring 2003 semester at the University of Hawaii at Manoa. Expert speakers were recruited from the Tropical Plant and Soil Sciences Department (TPSS) and the College of Tropical Agriculture and Human Resources (CTAHR).

Topic Expert affiliation

Roles and responsibilities of grad students

Ethics in research

Leadership in grad school \& beyond

Effective computer presentations

Finding grants using your computer

Interviewing skills

Learning styles

The future of agribusiness in Hawaii

Requirements for theses and dissertations at the University of Hawaii at Manoa

Going from thesis/dissertation to an article

Writing critically for publications

Selecting an effective graduate committee

Surviving graduate school from a

student's perspective

TPSS graduate coordinator

CTAHR faculty

CTAHR faculty-leadership

conference coordinator

TPSS faculty

TPSS grants specialist

Career Resources Center specialist

CTAHR associate dean

Panel discussion-local

horticulture business leaders

Associate dean of graduate division

CTAHR faculty - journal editor

CTAHR faculty-newspaper columnist

TPSS faculty

Class discussion

Table 2. Questions were adapted from Paul and Elder (2001), and used as the critical thinking exercise template for the Professional Development Seminar Series at the University of Hawaii at Manoa during the Spring 2003 semester. Students were required to answer these questions after each seminar. Completed critical thinking exercises were due during the following class period.

Question

Why/why not was this topic important to me?

What was the purpose of this presentation?

What was the key question(s) the presenter was addressing?

What were the most important kinds of information in the presentation?

What was the main conclusion(s) of the presentation?

What are the key ideas from this presentation that will help you make better decisions?

Was there anything the presenter took for granted?

What are the consequences if you take the information presented seriously?

What are the consequences if you do not take the information presented seriously?

The seminar was presented from which point of view?

their overall evaluation of the course, three students rated it excellent, seven good, and one did not respond.

From open-ended questions, students suggested offering the course during the fall semester for incoming students, cross-listing the course among departments in CTAHR, and reinforcing the critical thinking exercise. Further suggestions included making the course mandatory for first-year graduate students, especially those seeking a master's degree, and surveying students to find out which topics should be reconsidered.

\section{Discussion}

Analysis of course evaluations revealed that, in its first offering, TPSS
667 was considered to be as effective as established courses within the department. Moreover, the seminar sensitized students to on-campus resources that could help advance their professional development. Likewise, students are now more aware of actions they can take to effectively plan their development as professionals.

The TPSS Professional Development Seminar Series was adapted to include a critical thinking exercise. Accordingly, these exercises assisted in retaining course content and were valuable in that students were made to think more about improving their graduate experience. It was important for students to develop critical thinking skills that could be applied not only 
Table 3. Mean score for questions common to course evaluations of the Professional Development Seminar Series (TPSS 667) and other Tropical Plant and Soil Sciences Department (TPSS) courses during the Spring 2003 semester. Other TPSS courses offered during the Spring 2003 semester include the undergraduate courses: Ornamental Plants (TPSS 120); Tropical Production Systems (TPSS 300); Tropical Fruit Production (TPSS 403); Plant Propagation (TPSS 420); Plant Physiology (TPSS 470) and graduate courses in Nutrition of Tropical Crops (TPSS 610) and Advanced Soil Chemistry (TPSS 640). Evaluations were carried out using the University's Course and Faculty Evaluation System (CAFE). Score of $1=$ strongly disagree, $5=$ strongly agree. For TPSS $667, \mathbf{n}=$ 11. Sample size for questions from other TPSS courses equaled 20,57, 50, 20, and 27 , respectively.

\begin{tabular}{lcc}
\hline & \multicolumn{2}{c}{ Mean score \pm SD } \\
\cline { 2 - 3 } Question & $\begin{array}{c}\text { TPSS } \\
667\end{array}$ & $\begin{array}{c}\text { Other } \\
\text { TPSS courses }\end{array}$ \\
\hline $\begin{array}{l}\text { I was stimulated to discuss related topics } \\
\quad \text { outside of class. }\end{array}$ & $4.0 \pm 1.1$ & $3.8 \pm 1.3$ \\
I enjoyed this course. & $4.3 \pm 0.7$ & $3.4 \pm 1.2$ \\
$\begin{array}{l}\text { I generally understood the material presented } \\
\quad \text { in this course. }\end{array}$ & $4.6 \pm 0.7$ & $3.5 \pm 1.1$ \\
$\begin{array}{l}\text { My opinions about some topics changed because } \\
\quad \text { of this course. }\end{array}$ & $3.7 \pm 0.9$ & $3.8 \pm 1.0$ \\
In general, the course was well organized. & $4.5 \pm 0.5$ & $4.1 \pm 1.1$ \\
\hline
\end{tabular}

Table 4. Mean score for questions unique to student evaluations of the Professional Development Seminar Series given at the end of the Spring 2003 semester. Course evaluations were carried out using the university's Course and Faculty Evaluation System (CAFÉ). Score of 1 = strongly disagree, $5=$ strongly agree. For TPSS, $667 \mathrm{n}=11$. SD = standard deviation.

Question Mean score \pm SD

I learned to value new viewpoints.

$4.2 \pm 0.8$

I reconsidered many of my former attitudes.

$3.9 \pm 0.9$

I gained a better understanding of myself through this course.

$4.0 \pm 0.8$

I tried to relate what I learn in this course to my own experience.

$4.5 \pm 0.8$

Assignments make students think.

$4.3 \pm 0.8$

Writing assignments helped me retain course content.

$4.3 \pm 0.8$

Course was a valuable contribution to my education.

$4.4 \pm 0.9$

Course has significantly increased my knowledge and interests.

$4.0 \pm 0.7$

to their graduate career but also to their upcoming profession. Offering a professional development course for credit also seems to be a powerful incentive to attract graduate students from various disciplines, allowing them to incorporate the course into an already busy schedule. Having motivated graduate students and faculty members willing to implement and administer such a course was another component for success.

Student suggestions indicated that it would be beneficial to incorporate more time for discussion of each presentation. This could be best accomplished if the class period was extended from 50 to $75 \mathrm{~min}$ or by adding another reviewing the previous list of topics and surveying graduate students and faculty for input, as well as recruiting speakers throughout the university community. Course evaluations will also be conducted during a regularly scheduled class in order to encourage more student responses.

As evidenced by the experiences of students at two distinct institutions, a demand for improved professional development exists at the graduate level. A first step toward meeting this demand may be through the use of seminars conceived jointly between graduate students and faculty. In this way, students could better prepare themselves for the realities embedded in their future career paths.

\section{Literature cited}

Darling, C. and E. Earhart. 1990. A model for preparing graduate students as educators. Family Relations 39:341-348.

Gaff, J. 2002. Preparing future faculty and doctoral education. Change 34:63-66.

Golde, CM. and T.M. Dore. 2001. At cross purposes: What the experiences of today's graduate students reveal about doctoral education. The Pew Charitable Trusts. Philadelphia. 10 Jan. 2004. <http://www. phd-survey.org>.

Gonglewski, M. and A. Penningroth. 1998. German graduate student professional development: Report on a survey of perceptions. Unterrichtspraxis/Teaching German 31(1):70-77.

Gregory, M. 1994. From PhD program to BA college; or, the sometimes hard journey from life in the carrel to life in the world. ADE Bul. 107:21-24.

Mervis, J. 2001. Student survey highlights mismatch of training, goals. Science 291:408-409.

Paul, R. and L. Elder. 2001. The miniature guide to critical thinking: Concepts and tools. Foundation for Critical Thinking. Dillon Beach, Calif.

Poock, M. 2001. A model for integrating professional development in graduate education. College Student J. 35:345-352.

Skelly, S., T. Kohlleppel, M. Kane, and J. Bradley. 2002. Professional development for graduate students. North Amer. Colleges and Teachers of Agr. J. 46(4):16-18.

Stanley, D. and L. Higley. 2000. What are graduate students preparing to do? Amer. Entomol. 46(2):73-74. 